MALARIA

JOURNAL

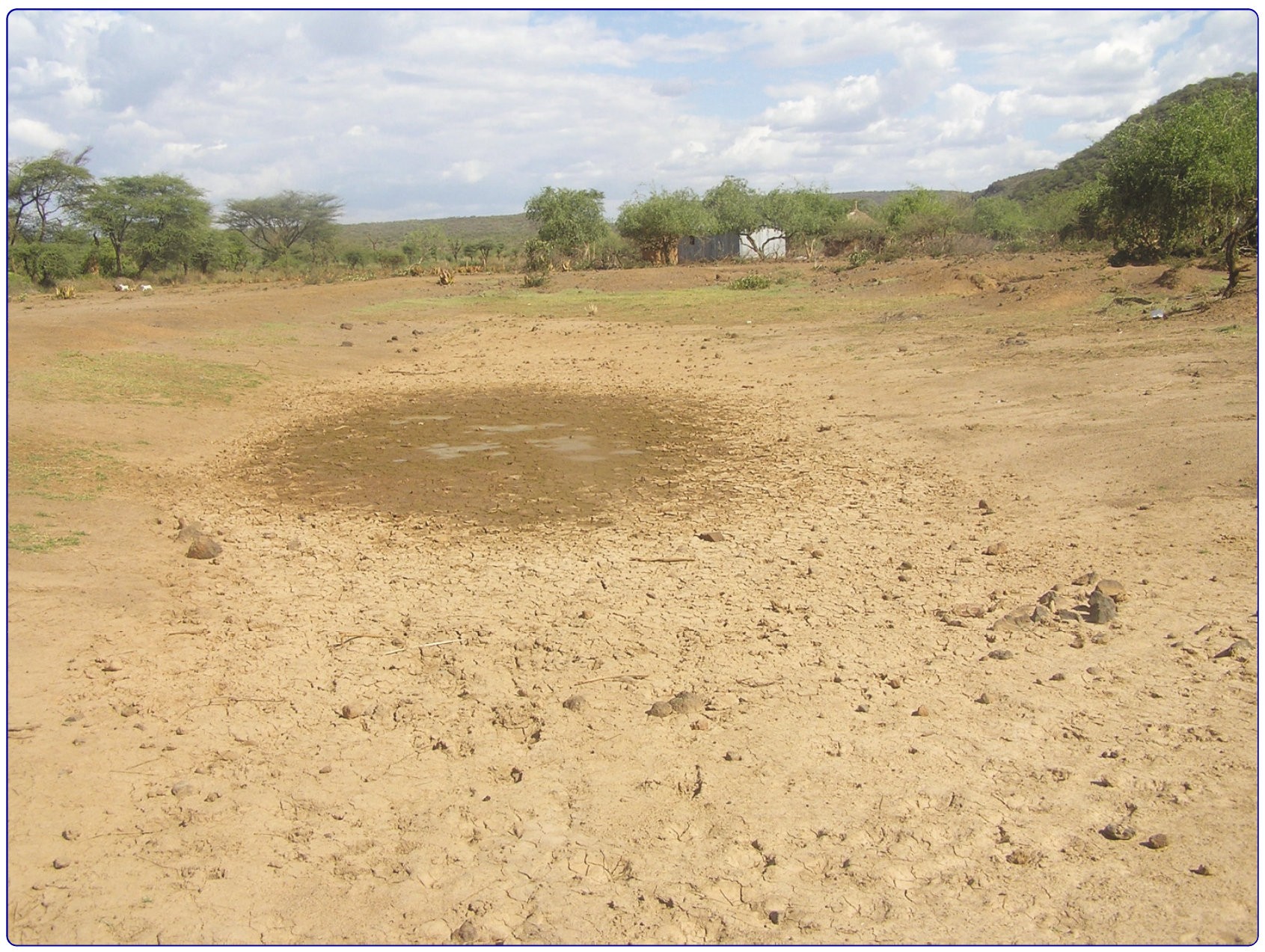

Plasmodium falciparum transmission and aridity: a Kenyan experience from the dry lands of Baringo and its implications for Anopheles arabiensis control

Mala et al. 


\title{
Plasmodium falciparum transmission and aridity: a Kenyan experience from the dry lands of Baringo and its implications for Anopheles arabiensis control
}

Albert O Mala ${ }^{1,2,5^{*}+}$, Lucy W Irungu ${ }^{2 \dagger}$, Josephat I Shililu ${ }^{1 \dagger}$, Ephantus J Muturi ${ }^{3 \dagger}$, Charles M Mbogo ${ }^{3+}$, Joseph K Njagi ${ }^{4 \dagger}$, Wolfgang R Mukabana ${ }^{1,2+}$ and John I Githure ${ }^{1 \dagger}$

\begin{abstract}
Background: The ecology of malaria vectors particularly in semi-arid areas of Africa is poorly understood. Accurate knowledge on this subject will boost current efforts to reduce the burden of malaria in sub-Saharan Africa. The objective of this study was to describe the dynamics of malaria transmission in two model semi-arid sites (Kamarimar and Tirion) in Baringo in Kenya.
\end{abstract}

Methods: Adult mosquitoes were collected indoors by pyrethrum spray collections (PSC) and outdoors by Centers for Disease Control (CDC) light traps and identified to species by morphological characteristics. Sibling species of Anopheles gambiae complex were further characterized by rDNA. PCR and enzyme-linked immuno-sorbent assays (ELISA) were used to test for Plasmodium falciparum circumsporozoite proteins and host blood meal sources respectively.

Results: Anopheles arabiensis was not only the most dominant mosquito species in both study sites but also the only sibling species of An. gambiae s.l. present in the area. Other species identified in the study area were Anopheles funestus, Anopheles pharoensis and Anopheles coustani. For Kamarimar but not Tirion, the human blood index ( $\mathrm{HBI}$ ) for light trap samples was significantly higher than for PSC samples (Kamarimar, 0.63 and 0.11 , Tirion, 0.48 and 0.43 ). The HBI for light trap samples was significantly higher in Kamarimar than in Tirion while that of PSC samples was significantly higher in Tirion than in Kamarimar. Entomological inoculation rates (EIR) were only detected for one month in Kamarimar and 3 months in Tirion. The number of houses in a homestead, number of people sleeping in the house, quality of the house, presence or absence of domestic animals, and distance to the animal shelter and the nearest larval habitat were significant predictors of An. arabiensis occurrence.

Conclusion: Malaria transmission in the study area is seasonal with An. arabiensis as the dominant vector. The fact this species feeds readily on humans and domestic animals suggest that zooprophylaxis may be a plausible malaria control strategy in semi-arid areas of Africa. The results also suggest that certain household characteristics may increase the risk of malaria transmission.

\footnotetext{
* Correspondence: amala@icipe.org

† Contributed equally

${ }^{1}$ Human Health Division, International Centre of Insect Physiology and

Ecology, P.O. Box 30772-00100, Nairobi, Kenya

Full list of author information is available at the end of the article
} 


\section{Background}

The main malaria vectors in sub-Saharan Africa (Anopheles gambiae, Anopheles arabiensis and Anopheles funestus) are confronted with highly variable and challenging climatic conditions especially in the semi arid regions and during the dry season [1]. A common challenge in these areas is the sudden shrinking or complete disappearance of the larval habitats during the dry season. This loss in larval habitats is followed by a rapid drop in abundance of malaria vectors and concomitant decrease in the incidence of severe malaria [2,3]. However the onset of the rainy season results in surprisingly rapid increase in malaria vector populations [4-6]. It is unclear whether the initial population buildup results from a new founder population of immigrants from neighboring areas with more permanent larval habitats or expansion from a very small local population that survives the dry period. Previous ecological studies suggest that Anopheles eggs have low tolerance to desiccation implying that only adults can survive the dry season [7]. These adults may hide in shelters such as rodent burrows, abandoned houses and wells, minimizing the chances of their detection through pyrethrum spray collections [8]. Further, despite local reduction in density during the dry season, population genetic studies suggest that $A n$. arabiensis which is the most common vector in semi-arid areas, maintains large permanent deme over a large area [9].

In addition to vector density, variations in environmental conditions have the potential to influence other factors that are directly related to malaria transmission. Environmental factors experienced by immature stages often influence the size of subsequent adults, which in turn determines the probability of adult survival. Further, other factors such as host availability and accessibility determine the likelihood of a mosquito vector to acquire and transmit malaria parasites. Anopheles arabiensis show plastic responses in host feeding patterns and readily diverts to feeding on the most common and easily accessible host(s) $[10,11]$. For this reason, zooprophylaxis is considered a practical strategy for reducing malaria transmission by this species [12].

Entomological inoculation rate (EIR), the average number of infective bites per person per unit time is the standard index used to estimate the intensity of malaria transmission in a given area. EIR is computed as the product of the mosquito human-biting rate and the proportion of mosquitoes carrying sporozoites (sporozoite rate) in their salivary glands [13]. Exceedingly low sporozoite rates (SR) have continued to hinder accurate determination of this critical entomologic index in Africa, especially in areas of unstable transmission where EIR is often below the undetectable levels $[14,15]$. The objective of this study was to examine the seasonal changes in malaria vector populations and the intensity of malaria transmission in two model semi-arid villages in Kenya. Knowledge generated from this study will guide the development of effective malaria control strategies in semi-arid areas of Africa.

\section{Methods}

\section{Ethical considerations}

Permission to carry out this study was obtained from the Ministry of Health, and ethical clearance was properly sought from the National Ethical Review Committee of Kenya but was deemed unnecessary. A sensitization rally was organized with the population during which the purpose of the study was clearly explained. Verbal consents from household heads of the study houses used in this research work were obtained only after informing them of the rationale and methodology of the research work.

\section{Study area}

The study was based in Marigat division of Baringo district, Kenya. Marigat town is approximately $250 \mathrm{~km}$ north-west of Nairobi. The town is situated $0.45 \mathrm{~N}, 36$ $E$ and about 700 meters above the sea-level, most of which is rangelands (Figure 1). The study area is characterized by high temperatures (above $32^{\circ} \mathrm{C}$ ) and low rainfall $(500-600 \mathrm{~mm})$ conditions that lead to rapid loss of transient larval habitats. The rainy season occurs from April to July while the peak dry season commences in November and ends in February of every year. Two study sites; Kamarimar and Tirion were selected for this study based on their proximity to the permanent Loboi swamp. The former is adjacent to the swamp and the latter is approximately $3 \mathrm{~km}$ away from the swamp. The study sites are described in details elsewhere [16].

\section{Mosquito sampling and identification}

In each study site, mosquitoes were collected in 10 randomly selected houses by pyrethrum spray collections (PSC). The collections were done once every week between 0700 and 1100 hours for a period of 22 months (July 2008 - April 2010). The houses were categorized into six types depending on materials used to construct the walls and the roofs (Figure 2). Other household characteristics that were recorded include size of eaves, distance to the nearest animal shed, use of insecticide treated bed nets and distance to the nearest habitat. Every week, a Centers for Disease Control (CDC) and prevention light trap (J.W. Hock Ltd, Gainesville, FL, U. S.A.) was also operated in the main bedroom of each of the 10 houses between 18.00 and 06.00 hours to estimate the human biting rates. To sample outdoor mosquito populations, 10 ten $\mathrm{CDC}$ light traps were operated 


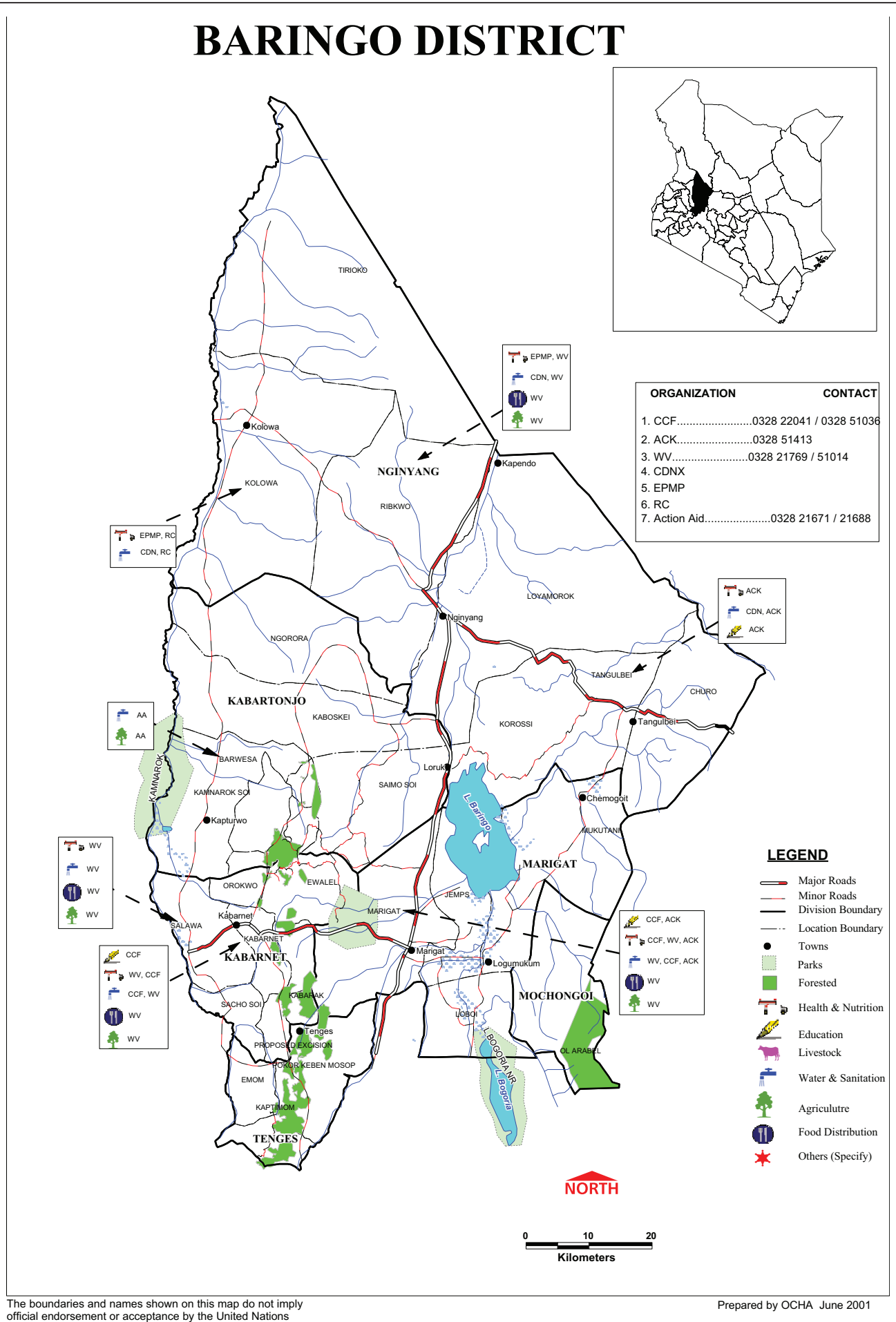

Figure 1 Map of Baringo district.

outdoor during the night preceding PSC collection once weekly. The samples were transported to the laboratory and female Anopheles were identified to species using morphological characteristics $[17,18]$. The samples were scored as unfed, blood-fed, semi-gravid or gravid by examining their abdomen under a dissecting microscope and later preserved in labeled vials containing anhydrous calcium sulphate. Random samples of An. gambiae complex were identified to their respective sibling species by rDNA PCR method [19]. 


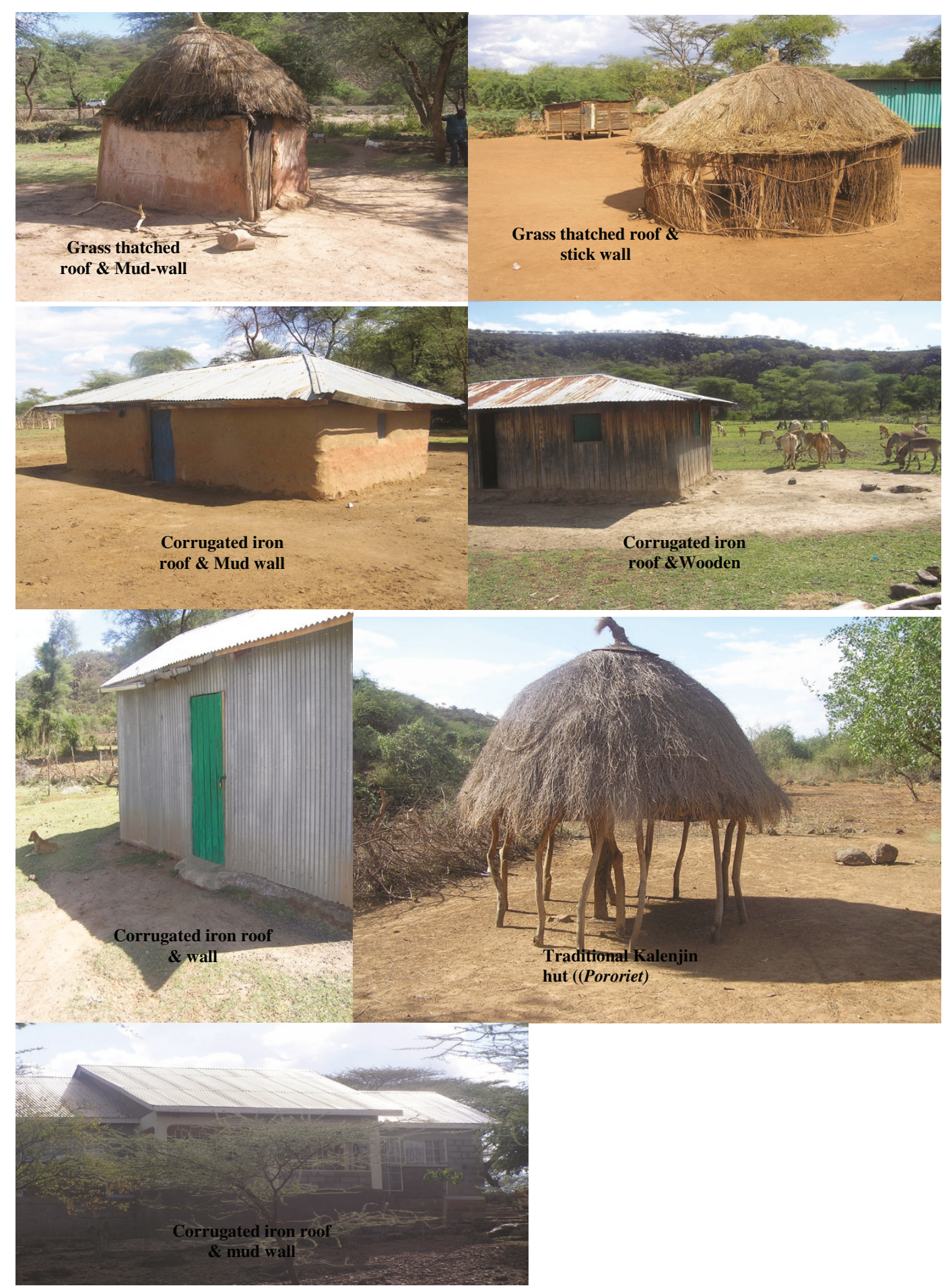

Figure 2 House types two rural villages in a semi arid area in Baringo,, Kenya.

\section{Determination of blood meal source using ELISA-based methods}

The abdomen from each blood-fed mosquito was homogenized in $50 \mu \mathrm{l}$ of phosphate buffered saline (PBS) and $950 \mu \mathrm{l}$ of grinding buffer. Blood meals were identified by direct enzyme-linked immunosorbent assay (ELISA) anti-host IgG conjugate against human and bovine in a single-step assay. Any non-reacting samples were subsequently tested using goat IgG. Fifty microlitres of the mosquito triturate was added to U-shaped bottom 96 - 
well microtitre plates and incubated overnight at room temperature. Each well was then washed twice with PBS containing $0.5 \%$ Tween 20 , followed by addition of $50 \mu \mathrm{l}$ of host specific conjugate in $0.5 \%$ boiled casein containing $0.025 \%$ Tween 20 . The ELISA results were read visually according to the protocol of Beier et al [20]. The human blood index (HBI) and bovine blood index (BBI) were calculated as the proportion of blood-fed mosquito samples that had fed on either human or bovine out of the total tested.

\section{ELISA detection of Plasmodium falciparum sporozoite infections}

The head and thorax portion of each individual mosquito was tested for $P$. falciparum circumsporozoite proteins (CSPs) by ELISA [21]. The sporozoite rate (SR) was computed as the proportion of mosquitoes positive for P. falciparum CSPs out of the total tested. EIR was derived as the product of human biting rate (HBR) estimated as the geometric mean number of vectors caught in a light trap/per house and the sporozoite rate.

\section{Meteorological data}

A rain gauge (Tru-Chek ${ }^{\circledR}$, Rain Gauge Division, Edwards Manufacturing Co. Albert Lea, MN, U.S.A.) was placed in each of the study villages and rainfall data recorded daily over a period of 22 months (July 2008 to April 2011). Temperature and relative humidity were measured using temperature and relative humidity data loggers (Onset Computer Corporation, Bourne, MA, U.S.A.).

\section{Statistical analysis}

Data was analysed using Statistical Analysis Software (SAS) Version 9.1 (SAS Institute). Data were checked for normality and homogeneity of variances and analysis of variance (ANOVA) was used to compare the mean differences in adult mosquito densities between villages and months. Chi-square and Fishers exact tests were used (as appropriate) to compare the differences in the human blood index (HBI), SR and HBR of An arabiensis between seasons and villages. Pearson Correlation analysis was used to asses the relationship between rainfall and adult mosquito densities while multivariate logistic regression analysis was used to assess the relationship between the measured micro-epidemiological characteristics and the occurrence of $A n$. arabiensis.

\section{Results}

\section{Meteorology}

The total precipitation for the period September 2008 to March 2010 was $100 \mathrm{~mm}$. The rainy season for the year 2008 was concentrated in July-August, bimodal in 2009 concentrated in January-February and SeptemberDecember. The months of February-March were wet in
Table 1 Relative abundance of Anopheles mosquito species in the two study sites in Baringo, Kenya

\begin{tabular}{lllll}
\hline Mosquito species & Kamarimar & \multicolumn{3}{l}{ Tirion } \\
\hline & $\begin{array}{l}\text { Light trap } \\
(\%)\end{array}$ & PSC (\%) & $\begin{array}{l}\text { Light trap } \\
(\%)\end{array}$ & PSC (\%) \\
Anopheles funestus & $800(11.9)$ & $280(22)$ & $1840(24.7)$ & $72(5.8)$ \\
Anopheles gambiae & $4186(62.2)$ & $\begin{array}{l}799 \\
(62.9)\end{array}$ & $5246(70.4)$ & $\begin{array}{l}907 \\
(73.7)\end{array}$ \\
& & 180 & $300(4.0)$ & 240 \\
Anopheles & $1700(25.3)$ & $(14.2)$ & & $(19.5)$ \\
pharoensis & & $12(0.9)$ & $67(0.9)$ & $12(1.0))$ \\
Anopheles coustani & $42(0.62$ & $\mathbf{1 2 7 1}$ & $\mathbf{7 4 5 3}$ & $\mathbf{1 2 3 1}$ \\
\hline Overall Total & $\mathbf{6 7 2 8}$ & & &
\end{tabular}

the year 2010. The average daily temperature was 26.24 (range $=21.60-30.68)$ and the average relative humidity was $20.94 \%$ (range $=2.74-94.8 \%$ ).

\section{Species composition and abundance}

Four Anopheles species were collected in the two study sites during the 22-month period (Table 1). These included An. gambiae s.l. (66.8\%), An. funestus (17.9\%), An. pharoensis (14.5\%) and An. coustani (0.8\%). Anopheles gambiae s.l. and An. coustani, respectively, were the most and the least abundant species in both study sites. Anopheles pharoensis was second most abundant species in Kamarimar, while An. funestus was the second most abundant species in Tirion. For all species, light trap collections were more productive than PSC. rDNA PCR analysis of $500 \mathrm{An}$. gambiae s.l samples revealed $A n$. arabiensis as the only sibling species present in the study area.

\section{Spatial and temporal distribution of mosquitoes}

The densities of $A n$. arabiensis were significantly higher in Tirion than in Kamarimar $(\mathrm{F}=10.76$, df $=1, P=0.001)$ and were mostly collected in CDC light traps (outdoors) than in pyrethrum spray collections $(\mathrm{F}=7.58 \mathrm{df}=1, P=$ 0.001). There were significant differences in adult densities across months in both Kamarimar $(\mathrm{F}=6.66, \mathrm{df}=18, \mathrm{P}=$ $0.001)$, and Tirion ( $\mathrm{F}=6.77, \mathrm{df}=18, \mathrm{P}=0.001)$. Adult densities were generally low with peaks in the months of July and November 2008, February, April and October 2009. However, there was no clear cut difference in monthly adult densities in the year 2010 (Figure 3). These populations were virtually undetectable in October 2008 and July 2009. The year 2010 experienced a lot of rainfall in the months of March and April, with An. arabiensis densities remaining generally high but with low densities being observed in the dry months of January and February. When mosquito densities between wet the months and dry months were compared, no significant differences were observed. Similarly, there was no significant correlation between rainfall and adult mosquito density $(\mathrm{r}=0.01$, $\mathrm{df}=20, \mathrm{P}>0.05$ ). 


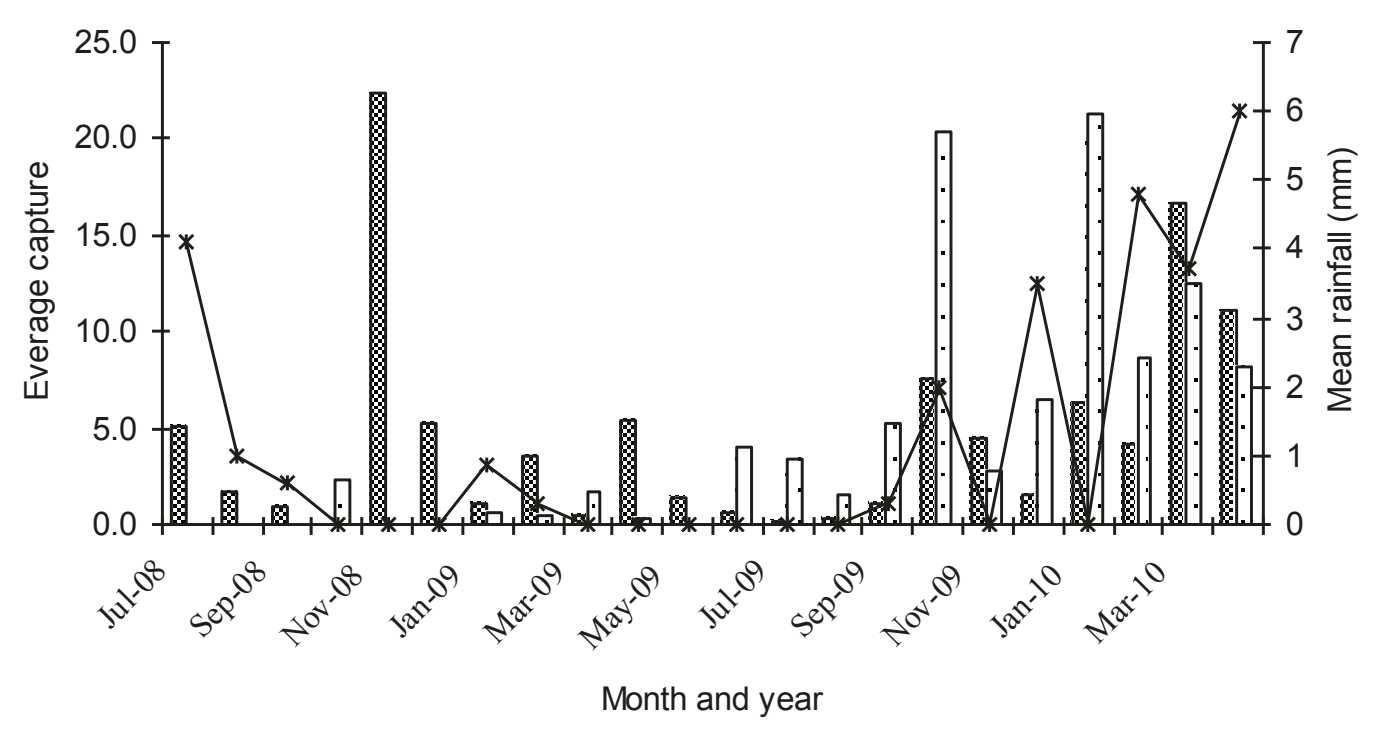

\% PrevalenceCDC $\longleftarrow$ Prevalence PSC $\longrightarrow$ Rainfall

Figure 3 Month to month variation in pooled mean number of indoor resting mosquitoes from Kamarimar and Tirion relative to rainfall patterns.

\section{Blood meal sources}

Blood meal hosts of 417 (95\%) samples out of the 421 tested were successfully identified by ELISA (Table 2). In Kamarimar, the human blood index (HBI) including those with mixed blood meals for outdoor collected (CDC light traps) samples was 0.63 and significantly higher than 0.11 for indoor collected (PSC) samples $\left(\chi^{2}\right.$ $=30.938, \mathrm{P}<0.0001)$. Similar values for Tirion were 0.48 and 0.43 , for outdoor and indoor collected samples respectively and did not differ significantly from each other $\left(\chi^{2}=0.522, \mathrm{P}=0.478\right)$. The HBI for outdoor collected samples was significantly higher in Kamarimar (0.65) than in Tirion $\left(0.48, \chi^{2}=4.899, \mathrm{P}=0.027\right)$. In contrast, the HBI for indoor collected samples was significantly higher in Tirion (0.43) than in Kamarimar (0.11, $\left.\chi^{2}=14.847, \mathrm{P}<0.0001\right)$. Mixed blood feeding was

Table 2 Blood-meal sources of Anopheles arabiensis mosquitoes in the two study sites, Baringo, Kenya.

\begin{tabular}{lllll}
\hline & \multicolumn{3}{l}{ Kamarimar } & \multicolumn{1}{l}{ Tirion } \\
\cline { 2 - 5 } & CDC (n; \%) & PSC (n; \%) & CDC (n; \%) & PSC (n; \%) \\
\hline Human & $45(51.1)$ & $0(0)$ & $56(37.6)$ & $33(24.3)$ \\
Bovine & $0(0.0)$ & $21(47.7)$ & $30(20.1)$ & $18(13.2)$ \\
Goat & $0(0.0)$ & $0(0.0)$ & $8(5.4)$ & $4(2.9)$ \\
Human and Bovine & $9(10.2)$ & $0(0.0)$ & $5(3.4)$ & $18(13.2)$ \\
Human and Goat & $0(0.0)$ & $0(0.0)$ & $2(1.3)$ & $3(2.2)$ \\
Bovine and Goat & $33(37.5)$ & $18(40.9)$ & $40(26.8)$ & $55(40.4)$ \\
All & $1(1.1)$ & $5(11.4)$ & $8(5.4)$ & $5(3.7)$ \\
\hline Total & 88 & 44 & 149 & 136 \\
\hline
\end{tabular}

also observed, the most common being bovine and goat blood meals. Some samples contained blood meals from all the three hosts tested.

\section{Human biting density, sporozite rates and EIR for} Anopheles arabiensis

The HBR of 9.51 bites per person per month in Kamarimar was not significantly different from 8.93 bites per person per month in Tirion ( $\mathrm{F}=0.79$, $\mathrm{df}=1, P=$ 0.3812). For each of the three years, there was a marked monthly variation in HBR. HBR was undetectable in some months, and quite high in other months e.g. 96 bite/person for the month of November 2008. Sporozoite rates were very low (16 out of $7,322,0.02 \%)$ and were only detected in two months in Kamarimar (October 2009 and March 2010) and four months in Tirion (October and November 2009 and January and March 2010 (Table 3). Similarly, EIR was undetectable throughout much of the study period except in October 2009 in Kamarimar and October 2009, November 2009 and January 2010 in Tirion when low levels were detected.

\section{Household characteristics and occurrence of $A n$. arabiensis}

Multivariate logistic regression analysis was used to determine the relationship between the measured household characteristics and occurrence of An. arabiensis (Table 4). The odds of An. arabiensis occurrence increased with decreasing distance to the animal shelter and the nearest larval habitat and increasing number of 
Table 3 Anopheles arabiensis sporozoite rates, Human biting rates and entomological inoculation rates in two villages in Baringo, Kenya

\begin{tabular}{lccccccc}
\hline \multicolumn{7}{c}{ Kamarimar } & \multicolumn{3}{c}{ Tirion } \\
\hline Month & Year & SR & HBR & EIR & SR & HBR & EIR \\
\hline July & 2008 & 0.0000 & 46.6226 & 0.0000 & 0.0000 & 0.0000 & 0.0000 \\
August & 2008 & 0.0000 & 12.0532 & 0.0000 & 0.0000 & 3.8843 & 0.0000 \\
September & 2008 & 0.0000 & 2.9356 & 0.0000 & 0.0000 & 3.1748 & 0.0000 \\
October & 2008 & 0.0000 & 0.0000 & 0.0000 & 0.0000 & 0.0000 & 0.0000 \\
November & 2008 & 0.0000 & 13.8905 & 0.0000 & 0.0000 & 95.7889 & 0.0000 \\
December & 2008 & 0.0000 & 0.0000 & 0.0000 & 0.0000 & 0.0000 & 0.0000 \\
January & 2009 & 0.0000 & 0.0000 & 0.0000 & 0.0000 & 0.0000 & 0.0000 \\
February & 2009 & 0.0000 & 0.0000 & 0.0000 & 0.0000 & 0.0000 & 0.0000 \\
March & 2009 & 0.0000 & 3.1910 & 0.0000 & 0.0000 & 3.5652 & 0.0000 \\
April & 2009 & 0.0000 & 4.0000 & 0.0000 & 0.0000 & 0.0000 & 0.0000 \\
May & 2009 & 0.0000 & 0.0000 & 0.0000 & 0.0000 & 0.0000 & 0.0000 \\
June & 2009 & 0.0000 & 15.6254 & 0.0000 & 0.0000 & 7.1680 & 0.0000 \\
July & 2009 & 0.0000 & 6.8903 & 0.0000 & 0.0000 & 7.0405 & 0.0000 \\
August & 2009 & 0.0000 & 3.1072 & 0.0000 & 0.0000 & 3.5569 & 0.0000 \\
September & 2009 & 0.0000 & 9.7898 & 0.0000 & 0.0000 & 12.4831 & 0.0000 \\
October & 2009 & 0.0019 & 62.1170 & 0.1176 & 0.0058 & 22.8941 & 0.1339 \\
November & 2009 & 0.0000 & 31.0782 & 0.0000 & 0.6667 & 38.4435 & 0.0000 \\
December & 2009 & 0.0000 & 11.2909 & 0.0000 & 0.0000 & 11.0009 & 0.0000 \\
January & 2010 & 0.0000 & 32.5275 & 0.0000 & 0.0085 & 33.3302 & 0.0000 \\
February & 2010 & 0.0000 & 39.7993 & 0.0000 & 0.0000 & 34.5888 & 0.0000 \\
March & 2010 & 0.0027 & 0.0000 & 0.0000 & 0.0066 & 0.0000 & 0.0000 \\
\hline July & 2010 & 0.0000 & 0.0000 & 0.0000 & 0.0000 & 0.0000 & 0.0000 \\
\hline
\end{tabular}

$\mathrm{HBR}=$ human biting rate; $\mathrm{SR}=$ sporozoite rate; $\mathrm{EIR}=$ entomologic inoculation rate. The sporozoite rate was derived from indoor resting collection. EIR = infective bites/person/month.

houses, sleepers and size of eaves. An. arabiensis was also more likely to be encountered in grass-thatched than in metal-roofed houses and in the absence than in presence of animals.

\section{Discussion}

Anopheles arabiensis was the main vector of malaria in the study area and feeds readily on both humans and domestic animals. Malaria transmission by this species was largely undetectable throughout much the study period except in a few wet months when low levels of transmission were detected. Suggesting that transmission of this disease in arid and semi-arid areas of Africa is mainly seasonal. The finding that An. arabiensis is the only sibling species of $A n$. gambiae s.l. present in the study area is consistent with previous cytogenetic studies [22-25]. Some An. funestus were collected during the study period. However, this species is known to thrive well in hot and humid environments as opposed to the hot and dry conditions [26-29]. It is also possible that lack of suitable long-lasting habitats preferred by this species may partly account for the low densities witnessed in the current study [30]. Previous invesigations
Table 4 House characteristics and indoor resting densities of Anopheles arabiensis in the two study sites in Baringo, Kenya

\begin{tabular}{lccccc}
\hline Characteristic & Coefficient & S.E. & df & Sig. & $\begin{array}{c}\text { Odds } \\
\text { ratio }\end{array}$ \\
\hline Number of houses & 0.16 & 0.04 & 1 & $<0.0001$ & 1.17 \\
Number of sleepers & 0.28 & 0.07 & 1 & $<0.0001$ & 1.76 \\
Presence of animals & -0.91 & 0.42 & 1 & 0.031 & 0.40 \\
Distance to animal shelter & -0.13 & 0.02 & 1 & $<0.0001$ & 0.88 \\
Roofing material & -0.76 & 0.39 & 1 & 0.048 & 0.47 \\
Size of eaves & 0.06 & 0.01 & 1 & $<0.0001$ & 1.06 \\
Distance to the nearest & -0.04 & 0.00 & 1 & 0.003 & 0.81 \\
larval habitat & & & & & \\
\hline
\end{tabular}

in the study area reported production of An. arabiensis in Kamarimar is sustained by permanent or semi-permanent larval habitats that included pan dams, marshes and adjoining drainage canals used for irrigation that are less dependent on rainfall [16].

A significant fraction of anthropophagic mosquitoes were sampled outdoors from the two villages, a clear evidence of house-exiting by vectors after feeding on humans. Conversely, large fractions of zoophilic mosquitoes were collected indoors illustrating the potential of employing zooprophylaxis as a strategy as has happened in some parts of Africa, Europe and USA [10]. The role of human activities in increasing human-vector contact cannot, however be ruled out. Lightly-dressed residents in the study villages stay out late in the evening to irrigate their farms before temperatures sky-rocket during day time, exposing themselves to mosquito bites. Herding is a common practice in Baringo and indeed, most semi-arid areas of Africa. The largest communal grazing field in the study areas is located in Tirion and is used by hundreds of pastoralists from different villages. Increasing herd sizes could be a plausible vector control strategy but may be counterproductive under certain circumstances where high livestock densities lead to an increase in vector densities and high human biting rates [31,32].

The intensity of malaria transmission by An. arabiensis as measured by EIR was extremely low and seasonal. This could be due to low infectiousness of the human population in the area or because a majority of mosquitoes caught by light traps were newly emerged and had not had an opportunity to acquire an infectious blood meal. Further, it is also likely that adult lifespan of this species was shorter than the extrinsic incubation period for malaria parasites but this possibility was not evaluated in the current study. These findings corroborate those from other semi-arid areas of Africa in Sudan and Eritrea. Shililu and others [33] established that the risk of exposure to sporozoite-laden An. arabiensis in Eritrea was highly heterogeneous and seasonal. Biting rates and 
EIRs peaked during the rainy season, but little or no transmission occurred during the dry season. Year-long studies conducted in the Sudan by Dukeen and Omer [34] in the 1970s showed An. arabiensis adult densities peaking seasonally during certain months when Nile water levels were low, and rising when the water levels rose.

Entry and/or exit of mosquitoes largely depended on house type. The average number of indoor resting mosquitoes collected in both villages varied significantly depending on the type of house occupied by potential human hosts, highlighting the importance of this microepidemiological factor in malaria transmission. There was a strong preference for grass-thatched houses, making house modification to limit mosquito flight into houses a plausible control strategy. This finding reinforces the common belief that poverty is a major driver of malaria transmission in Africa. Most communities in the continent's rural and resource constrained areas are largely unable to afford decent housing with adequate screening measures to block mosquito entry into houses.

It is encouraging that an EIR value was realized in only one out of the 22 months in which sampling was done. This is a positive outcome in the sense that increasing uptake of malaria prevention measures through integrated vector management programs could lower the current prevailing EIR levels to below one infective bite per person per month. Such programs have the potential of eliminating malaria in these areas by reducing parasite rates to levels that can interrupt malaria transmission. We believe these findings have important implications and will inform policy on vector control in epidemiological zones of the world where low seasonal malaria transmission patterns are experienced.

\section{Conclusion}

Malaria transmission in the study area was seasonal and vectored by $A n$. arabiensis. This species was found to feed readily of humans and domestic animals suggesting that zooprophylaxis may be a potential malaria control strategy in the study area and other semi-arid regions of Africa. However, further studies are needed to assess the negative impacts of this strategy in target sites.

\footnotetext{
Acknowledgements

We are grateful to Prof. Christian Borgemeister, Director General, International Centre of Insect Physiology and Ecology, for his strong support on this project. We acknowledge the technical support provided by Enock Mpanga, James Wauna, Mark Rotich, Samuel Toweet, Richard Bor, Albert Cheboiwo, Peter Lembes, Phillip Muter, Peter Lembes, Johnstone Kasitet and Leonard Laanoi. We are grateful to Joseph Nzovu, Gabriel Nzai, Festus Yaa and Shida David for their assistance in blood meal analysis. This research was supported by UNICEF/UNDP/World Bank/WHO Special Programme for Research and Training in Tropical Diseases (TDR) grant \# U01A1054889 (Josephat I Shililu) International Centre of Insect Physiology and Ecology, Nairobi.
}

\section{Author details}

${ }^{1}$ Human Health Division, International Centre of Insect Physiology and Ecology, P.O. Box 30772-00100, Nairobi, Kenya. ${ }^{2}$ School of Biological Sciences, University of Nairobi, Nairobi, Kenya. ${ }^{3}$ Illinois Natural History Survey, University of Illinois at Urbana-Champaign, Illinois, USA. ${ }^{4}$ Kenya Medical Research Institute, Kenya. ${ }^{5}$ Ministry of Health, Division of Malaria Control, Nairobi, Kenya.

\section{Authors' contributions}

AOM conducted the field studies, analyzed the data and wrote the manuscript. JIS and CMM provided scientific guidance in data collection, analysis and manuscript preparation and planning, and implementation of day-to-day field and laboratory activities. JKN and LWI offered scientific guidance in data analysis and manuscript preparation. EJM and WRM provided scientific guidance in data analysis, interpretation of results and manuscript preparation. JIG provided overall supervision of the study and preparation of manuscript. All authors actively contributed to the interpretation of the findings and development of the final manuscript and approved the final manuscript.

\section{Competing interests}

The authors declare that they have no competing interests.

Received: 11 December 2010 Accepted: 14 May 2011

Published: 14 May 2011

\section{References}

1. Mattingly PF: Ecological aspects of mosquito evolution. Parassitologia 1971, 13:31-65.

2. Wilkinson RN, Goulds DJ, Boonyakanist P, Segal HE: Observations on Anopheles balabacensis (Diptera: Culicidae) in Thailand. J Med Entomol 1978, 14:666-671.

3. Snow RW, Armstrong Schellenberg JRM, Peshu N, Forster D, Newton CRJC, Winstanley PA, Mwangi L, Waruiru C, Warn PA, Newbold C, Marsh K: Periodicity and space-time clustering of severe childhood malaria on the coast of Kenya. Trans R Soc Trop Med Hyg 1993, 87:386-390.

4. Omer SM, Cloudsley-Thomson JL: Survival of female Anopheles gambiae Giles through a 9-month Dry-season in Sudan. Bull World Health Org 1970, 42:319-330.

5. Mbogo CNM, Snow RW, Kabiru EW, Ouma JH, Githure Jl, Marsh K, Beier JC: Low-level Plasmodium falciparum transmission and the incidence of severe malaria infections on the Kenyan coast. Am J Trop Med Hyg 1993, 49:254-253.

6. Omer SM, Cloudsley-Thompson JL: Dry season biology of Anopheles gambiae Giles in the Sudan. Nature 1968, 217:879-880.

7. Beier JC, Copeland R, Oyaro C, Masinya A, Odago WO, Oduor S, Koech DK Roberts CR: Anopheles gambiae complex egg-stage survival in dry soil from larval development sites in western Kenya. J Am Mosq Control Assoc 1990, 6:105-109.

8. Omer SM, Cloudsley-Thompson JL: Survival of female Anopheles gambiae Giles through a 9-month dry season in Sudan. Bull World Health Org 1970, 42:319-330.

9. Simard F, Lehmann T, Lemasson JJ, Diatta M, Fontenille D: Persistence of Anopheles arabiensis during the severe dry season conditions in Senegal: an indirect approach using microsatellite loci. Insect Mol Biol 2000, 9:467-479.

10. Muriu SM, Muturi EJ, Shililu Jl, Mbogo CM, Mwangangi JM, Jacob BG, Irungu LW, Mukabana RW, Githure Jl, Novak RJ: Host choice and multiple blood feeding behaviour of malaria vectors and other anophelines in Mwea rice scheme, Kenya. Malar J 2008, 7:43

11. Muturi EJ, Muriu S, Shililu J, Mwangangi J, Jacob BG, Mbogo C, Githure J, Novak RJ: Effect of rice cultivation on malaria transmission in central Kenya. Am J Trop Med Hyg 2008, 78:270-275.

12. Mahande A, Mosha F, Mahande J, Kweka E: Feeding and resting behaviour of malaria vector, Anopheles arabiensis with reference to zooprophylaxis. Malar J 2007, 6:100.

13. Macdonald G: The epidemiology and control of malaria. London: Oxford University Press; 1957.

14. Wirtz RA, Burkot TR: Detection of malarial parasites in mosquitoes. Advances in Disease Vector Research New York: Springer-Verlag; 1991 
15. Trape JF, Rogier C: Combating malaria morbidity and mortality by reducing transmission. Parasitol Today 1996, 12:236-240.

16. Mala AO, Irungu LW, Shililu Jl, Muturi EJ, Mbogo CC, Njagi JK, Githure Jl: Dry season ecology of Anopheles gambiae complex mosquitoes at larval habitats in two traditionally semi-arid villages in Baringo, Kenya. Parasit Vectors 2011, 4:25.

17. Gillies MT, Coetzee M: Supplement to the Anophelinae of Africa South of the Sahara. Johannesburg, South Africa: South African Institute of Medical Research; 1987, Publication no. 55.

18. Gillies MT, De Meillon B: The Anophelinae of Africa South of the Sahara. Johannesburg, South Africa: South African Institute of Medical Research; 1968, Publication no. 54

19. Scott JA, Brogdon WG, Collins FH: Identification of single specimens of the Anopheles gambiae complex by the polymerase chain reaction. Am J Trop Med Hyg 1993, 49:520-529.

20. Beier JC, Perkins PV, Wirtz RA, Koros JK, Diggs D, Gargan TP, Koech DK: Bloodmeal identification by direct enzyme-linked immunosorbent assay (ELISA), tested on Anopheles (Diptera: Culicidae) in Kenya. J Med Entomol 1988, 25:9-16.

21. Wirtz RA, Zavala F, Charoenvit Y, Campbell GH, Burkot TR, Schneider I, Esser KM, Beaudoin RL, Andre RG: Comparative testing of monoclonal antibodies against Plasmodium falciparum sporozoites for ELISA development. Bull World Health Org 1987, 65:39-45.

22. Aniedu I, Mutinga MJ, Mutero CM: Age composition and survival rate of Anopheles gambiae Giles complex (Diptera, Culicidae) in Baringo district. Kenya. J Appl Entomol 1989, 107:387-94.

23. Aniedu I: Biting activity and resting habits of Malaria vectors in Baringo district, Kenya. Insect Sci Applic 1993, 13:151-161.

24. Aniedu I: Dynamics of malaria transmission near two permanent breeding sites in Baringo district, Kenya. Indian J Med Res 1997, 105:206-211.

25. Charlwood JD, Vij R, Billingsley PF: Dry season refugia of malaria transmitting mosquitoes in dry savannah zone of east Africa. Am J Trop Med Hyg 2000, 62:726-732.

26. Ramsdale CD, Fontaine RE: Ecological investigations of Anopheles gambiae and Anopheles funestus. I. Dry season studies in villages near Kaduna, Nigeria. WHO document; 1970, WHO/MAL/70.735.

27. Ramsdale CD, Fontaine RE: Ecological investigations of Anopheles gambiae and Anopheles funestus. II. Dry season studies with colonyreared gambiae species B, Kaduna, Nigeria. WHO document; 1970, WHO/ MAL/70.736

28. Taylor CE, Toure YT, Coluzzi M, Petrarca V: Effective population size and persistence of Anopheles arabiensis during the dry season in west Africa. Med Vet Entomol 1993, 7:351-357.

29. Munga S, Minakawa N, Zhou G, Mushinzimana E, Barrack OJ, Githeko AK Yan G: Association between landcover and production of malaria vectors in the western Kenyan highland. Am J Trop Med Hyg 2006, 74:69-75.

30. ljumba J, Mosha F, Lindsay S: Malaria transmission risk variations derived from different agricultural practices in an irrigated area of northern Tanzania. Med Vet Entomol 2002, 16:28-38

31. Sota T, Mogi M: Effectiveness of zooprophylaxis in malaria control: a theoretical inquiry, with a model for mosquito populations with two bloodmeal hosts. Med Vet Entomol 1989, 3:337-345.

32. Saul A: A computer model of the role of alternative bloodmeal source on vector-borne disease transmission. Livestock Management and Disease Vector Control 1990, 10, PEEMMP/10/907. (mim. doc.).

33. Shililu J, Ghebremeskel T, Mengistu S, Fekadu H, Zerom M, Mbogo C, Githure J, Novak R, Brantly E, Beier JC: High seasonal variation in entomologic inoculation rates in Eritrea, a semi-arid region of unstable malaria in Africa. Am J Trop Med Hyg 2003, 69:607-613.

34. Dukeen MYH, Omer SM: Ecology of the malaria vector Anopheles arahiensis Patton (Diptera: Culicidae) by the Nile in northern Sudan. Bull Ent Res 1986, 76:451-467.

doi:10.1186/1475-2875-10-121

Cite this article as: Mala et al:: Plasmodium falciparum transmission and aridity: a Kenyan experience from the dry lands of Baringo and its implications for Anopheles arabiensis control. Malaria Journal 2011 10:121.

\section{Submit your next manuscript to BioMed Central and take full advantage of:}

- Convenient online submission

- Thorough peer review

- No space constraints or color figure charges

- Immediate publication on acceptance

- Inclusion in PubMed, CAS, Scopus and Google Scholar

- Research which is freely available for redistribution 